\title{
Differences between official and non-official matches in worst-case scenarios in elite futsal players
}

Authors' Contribution: A Study Design B Data Collection C Statistical Analysis D Data Interpretation E Manuscript Preparation F Literature Search G Funds Collection

\author{
Konstantinos Spyrou 1,2,4 ABCDE, Tomás T. Freitas ${ }^{1,2,3,4}$ ACE, Elena Marín-Cascales ${ }^{4 \mathrm{BDE}}$,

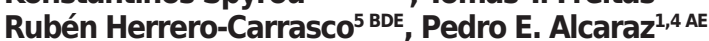 \\ ${ }^{1}$ UCAM Research Center for High Performance Sport, \\ Catholic University of Murcia, Murcia, Spain \\ 2 Faculty of Sport Sciences, Catholic University of Murcia, Murcia, Spain \\ ${ }^{3}$ NAR - Nucleus of High Performance in Sport, São Paulo, Brazil \\ ${ }^{4}$ Strength and Conditioning Society, Rome, Italy \\ ${ }^{5}$ Research Group Murcia Soccer Federation, Murcia, Spain
}

\section{abstract}

Background:

Material and methods:

Results: Considering ROLL, significant and small differences were found in PL-min-1, with higher intensity in 30-s $(p=0.001$; ES $=-0.53)$ and $1-\min (p=0.001$; ES = -0.47) in OFF when compared to Non-OFF, but nonsignificant and small to trivial changes in 3- $\min (p=0.060 ; E S=-0.23)$ and $5-\min (p=0.605 ; E S=-0.06)$ were observed. Regarding FIX, significant and small changes were obtained, with higher intensity in OFF in all time-periods when compared to Non-OFF. Significant differences were found between the two methods (ROLL vs FIX) in 30-s, 1- and 3-min, but not in 5-min. Significant differences, with lower PL- $\mathrm{min}^{-1}$, were observed with increasing time-windows from both methods $(p=0.001)$

Conclusions: In summary, OFF matches present higher WCS than Non-OFF ones when considering short time-periods, and the FIX method could underestimate the "actual intensity" of the match compared to ROLL.

Key words: five-a-side soccer; most demanding passages; external load; performance.

\section{article details}

Article statistics: Word count: 2,837; Tables: 1; Figures: 2; References: 31

Received: August 2021; Accepted: November 2021; Published: December 2021

Full-text PDF: http://www.balticsportscience.com

Copyright @ Gdansk University of Physical Education and Sport, Poland

Indexation: Celdes, Clarivate Analytics Emerging Sources Citation Index (ESCI), CNKI Scholar (China National Knowledge Infrastructure), CNPIEC, DOAJ, EBSCO - Central \& Eastern European Academic Source, EBSCO - SPORTDiscus, EBSCO Discovery Service, Google Scholar, Index Copernicus, J-Gate, Naviga (Softweco, Primo Central (ExLibris), ProQuest - Family Health, ProQuest - Health \& Medical Complete, ProQuest - Illustrata: Health Sciences, ProQuest Nursing \& Allied Health Source, Summon (Serials Solutions/ProQuest, TDOne (TDNet), Ulrich's Periodicals Directory/ ulrichsweb, WorldCat (OCLC)

Funding: This research received no specific grant from any funding agency in the public, commercial, or not-for-profit sectors.

Conflict of interests: Corresponding author:

Open Access License: Authors have declared that no competing interest exists.

Konstantinos Spyrou; UCAM Research Center for High Performance Sport, Catholic University of Murcia, Murcia, Spain, Campus de los Jerónimos, 30107, Guadalupe, Murcia, Spain, +34 968278566, kspyrou@ucam.edu

This is an open access article distributed under the terms of the Creative Commons Attribution-Non-Commercial-NoDerivatives 4.0 International (https://creativecommons.org/licenses/by-nc-nd/4.0/), which permits use, distribution, and reproduction in any medium, provided the original work is properly cited, the use is non-commercial and is otherwise in compliance with the license. 


\section{INTRODUCTION}

Futsal is a high-intensity intermittent indoor sport, in which players are exposed to repetitive high-demanding scenarios during match-play [1, 2]. A recent study [3] reported, through wearable technology (i.e., accelerometry) data, that futsal players perform around $\sim 70$ high-intensity accelerations, decelerations, and $\sim 170$ changes of direction during official games. Moreover, players have been found to cover around $\sim 3700 \mathrm{~m}$ in a single match, of which $\sim 135 \mathrm{~m}$ are spent on high-speed running actions $\left(>18 \mathrm{~km} \cdot \mathrm{h}^{-1}\right)$ [4].

Of note, the type of games in futsal (i.e., official [OFF] and non-official [Non-OFF]) may influence match-play demands. Specifically, professional players have been reported to spend $\sim 12 \%$ and $\sim 5 \%$ of the whole game duration in high-intensity running and sprinting actions in a simulated match (i.e., $4 \times 10$-min), values lower than the $\sim 14 \%$ and $\sim 9 \%$ found during OFF competition [5, 6]. Likewise, the time of recovery between sprint bouts is higher in NonOFF (i.e., 40-s) when compared to OFF matches ( 15-s) [6, 7]. Considering physiological parameters, a study [5] found that players spent $83 \%$ of the playing time above $85 \%$ of the maximum heart rate in OFF games as opposed to another investigation that reported that only $36 \%$ of the total time was spent at $>80 \%$ of the maximum heart rate in Non-OFF matches [8]. For this reason, to prepare players adequately to cope with training and competition loads during the season, practitioners should be conscious that their athletes are exposed to dissimilar stress levels depending on the type of the game.

Regarding the quantification of the match demands, different methods (i.e., "average approach" or "worst-case scenarios" [WCS] methods) have been used to measure and analyze the mechanical stress that players are exposed to during the match. The WCS approach relates to the quantification of the most intense period of the game or training [11] and is becoming increasingly popular in team-sports, such as soccer [9, 10], rugby [11], Australian football [12], futsal [13], and field- and ice-hockey [14, 15], to assess fluctuations in matchdemands by dividing time-play into discrete "epochs". The WCS may be considered more accurate to quantify the most intense periods of the game, because the "average approach" may overlook variations and obscure the most intense periods of the play [16].

Depending on the availability of wearable technology (i.e., GPS vs accelerometry) and sport (i.e., indoor vs outdoor), player load (PL), player load per minute (PL· $\left.\mathrm{min}^{-1}\right)$, total distance, and high-speed running have been the most commonly investigated variables with timewindows ranging from 30-s to 10-min in length [9-14]. Within the WCS approach, the fixedperiod method (FIX) was first developed [17], and consisted of splitting the time into fixedperiods (e.g., 1-30-s, 31-60-s, etc.). However, quantifying WCS by rolling average (ROLL) is considered more accurate, as this technique detects the exact period (e.g., 1-30-s, 2-31-s, etc.) in which players reached the highest intensity $[18,19]$. For example, Fereday et al. [20] found that the FIX method underestimates the relative total and high-speed distances during match-play when compared to ROLL in soccer players [20]. Still, when it comes to futsal, literature is scarce about the quantification of WCS of different matches (i.e., OFF and Non-OFF) and using different methods (i.e., ROLL and FIX).

Therefore, this study aimed to compare and analyze the WCS in futsal considering: 1) OFF and Non-OFF matches; 2) calculated by two methods (i.e., ROLL and FIX); and 3) four different time-periods (i.e., 30-s, 1-, 3-, and 5-min). Due to futsal's characteristics [2], we hypothesized that WCS would be higher: 1 ) in OFF when compared to Non-OFF matches; 2) when considering smaller (e.g., 30-s and 1-min) rather than larger time-epochs (e.g., 3and 5-min), and 3) when calculated by ROLL in comparison to FIX. 


\section{MATERIALS AND METHODS}

\section{STUDY DESIGN}

An observation longitudinal study was designed. Match-play data from 26 games (i.e., 13 OFF and 13 Non-OFF) were collected using wearable technology (i.e., accelerometers) throughout the seasons of 2019/2020 and 2020/2021. OFF consisted of national (e.g., Liga Nacional de Fútbol Sala [LNFS]; 1st Division of Spain) or international (e.g., UEFA Champion League) games, and Non-OFF consisted only of friendly matches. Consistent with the LNFS rules, games lasted 40-min divided into two 20-min halves and separated by a 10-min break. Only on-court players (i.e., starters and substitutes) were monitored (i.e., 12 players). The study procedures did not influence or alter the match in any way. Four WCS time-periods (i.e., 30-s, 1-, 3-, and 5-min) were analyzed by the ROLL and FIX methods.

\section{PARTICIPANTS}

Twelve elite male futsal players (age: $26.7 \pm 3.1$ years old, body mass: $73.6 \pm 5.4 \mathrm{~kg}$, height: $1.77 \pm 0.04 \mathrm{~m}$, body fat: $8.9 \pm 1.7 \%$ ), competing in LNFS and the UEFA Futsal Champions League were monitored. By signing a professional contract with the club, all players provided individual consent for data collection and study participation. All procedures were approved by the Local Human Subjects Ethics Committee and conducted according to the Declaration of Helsinki.

\section{PROCEDURE}

Instrumentation: The activity profile data were collected via Catapult Sport Optimeye S5 portable GPS units (Catapult Innovation; Melbourne, Australia) comprising a tri-axial accelerometer, a gyroscope, and a magnetometer, which provide data for inertial movement analysis at a sampling rate of $100 \mathrm{~Hz}$. Previous research has reported this technology to be valid and reliable [21]. The devices were fitted to the upper back of each player using a specific vest under the athletes' jersey. To avoid potential inter-unit error, each player wore the same device throughout the seasons [22]. To represent the match-play cumulative load, data collection was initiated when players were in the locker room after the warmup period, 10-min before starting the match, and concluded before the postgame cooldown. All data were analyzed by Catapult Sport Openfield software (Catapult Innovation; Melbourne, Australia) and exported to a custom-built Microsoft Excel spreadsheet for further analysis. PL consists of the sum of the accelerations across all axes of the internal tri-axial accelerometer during movement $(100 \mathrm{~Hz})$, applying the established formula and expressed as an arbitrary unit (a.u.) [23]. PL· $\mathrm{min}^{-1}$ divides the accumulated PL by time, and provides an intensity index [24].

Rolling Average and Fixed-Periods Length: To determine the WCS, data were extracted in each second interval for each player into a Microsoft Excel spreadsheet. ROLL was calculated by rolling time length of 30-s, 1-, 3-, and 5-min, (e.g., 1 - 30-s, 2 - 31-s, and so on) for the whole match, and by selecting the most intense passage for all the players individually (coefficient of variability [CV] 30-s: 10.9\%; CV 1-min: 10.4\%; CV 3-min: 10.4\%; CV 5-min: 11.6\%). FIX was obtained by splitting the total match into fixed-periods (e.g., 1 - 30-s, 31 - 60-s, etc.), from the start to the end of the game (CV 30-s: 12.1\%; CV 1-min: 12.2\%; CV 3-min: 13.1\%; CV 5-min: 13.4\%). For both methods, the highest intensity for every player in four time-windows (i.e., 30-s, 1-, 3-, and 5-min) was considered for analysis.

\section{STATISTICAL ANALYSIS}

The statistical analysis was performed using the Jamovi statistical package (2020; 1.6). Data are presented as mean and standard deviation (SD). Descriptive statistics were calculated for the types of game (i.e., OFF and Non-OFF), WCS duration (i.e., 30-s, 1-, 3-, and 5-min) and methods (i.e., ROLL and FIX). The assumption of normality in each variable was analyzed 
using the Shapiro-Wilk test. An independent T-Test was used to detect differences between WCS in OFF and Non-OFF games. A Non-Parametric Friedman repeated-measures ANOVA was completed to identify differences between the different WCS durations. A paired Sample T-Test was used to analyze the differences between the ROLL and FIX methods. Cohen's effect sizes (ES) with 95\% confidence intervals (95\% CI) were computed to determine the magnitude of every paired comparison and classified as: trivial $(<0.2)$, small $(>0.2-0.6)$, moderate (>0.6-1.2), large (>1.2-2.0), and very large (>2.0-4.0) [25]. The significance level was set at $\mathrm{p} \leq 0.05$.

\section{RESULTS}

Figure 1 depicts the WCS (considering the PL· $\mathrm{min}^{-1}$ ) in intervals of 30-s, 1-, 3- and 5-min and the differences between OFF and Non-OFF games and time-periods, calculated by ROLL. Significantly more intense WCS were found in OFF when considering 30 -s $(\mathrm{p}=$ $0.001 ; \operatorname{ES}[95 \% \mathrm{CI}]=-0.53[-0.79-0.28])$ and $1-\min (\mathrm{p}=0.001 ; \mathrm{ES}[95 \% \mathrm{CI}]=-0.47$ [-0.72 - -0.21]) intervals in comparison to Non-OFF. Conversely, non-significant and trivial to small differences between game types were observed when analyzing 3-min $(\mathrm{p}=0.060$; $\operatorname{ES}[95 \% \mathrm{CI}]=-0.23[-0.48-0.01])$ and $5-\min (\mathrm{p}=0.605 ; \mathrm{ES}[95 \% \mathrm{CI}]=-0.06[-0.31-0.18])$ epochs. Regarding the different time-periods, 30-s intervals yielded greater WCS than all other periods (30-s - 1-min: $\mathrm{p}=0.001 ; 30$-s - 3-min: $\mathrm{p}=0.001 ; 30$-s - 5-min: $\mathrm{p}=0.001$ ), and 1-min intervals were found to be more intense than 3- and 5-min ones (1-3-min: $\mathrm{p}=$ $0.001 ; 1-5$-min: $p=0.001)$. Finally, significant differences were obtained when comparing 3- to 5-min intervals $(\mathrm{p}=0.001)$.

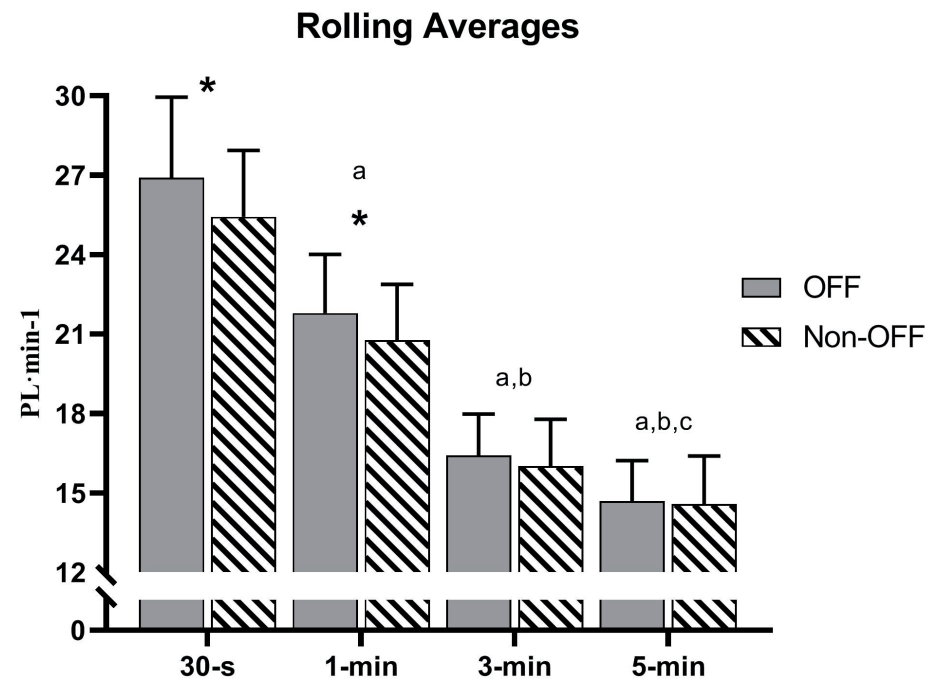

Fig. 1. Worst-case scenarios in official and non-official matches calculated over rolling-averages of 30-s, 1-min, 3-min and 5-min in length.

Values expressed as mean \pm SD.

${ }^{*} p \leq 0.05$; significant difference between official and non-official analyzed by an Independent T-Test.

a: significantly different than the 30-s time-interval; b: significantly different than the 1-min time-interval;

c: significantly different than 3-min time-interval. OFF: official; Non-OFF: non-official.

Figure 2 presents the WCS (considering the PL· min $^{-1}$ ) during 30-s, 1-, 3- and 5-min intervals and the differences between OFF and Non-OFF games and time-epochs, calculated by the FIX. Significantly more intense WCS were found in OFF when considering 30-sec $(p=0.001$; $\operatorname{ES}[95 \% \mathrm{CI}]=-0.52[-0.78--0.26]), 1-\min (\mathrm{p}=0.001 ; \operatorname{ES}[95 \% \mathrm{CI}]=-0.49[-0.75--0.23])$, $3-\min (\mathrm{p}=0.001$; ES [95\% CI] $=-0.35[-0.60--0.09])$, and 5-min intervals $(p=0.001$; ES $[95 \% \mathrm{CI}]=-0.40[-0.66--0.15])$ in comparison to Non-OFF. Regarding the different timewindows, 30-s presented greater WCS than all other periods (30-s - 1-min: $p=0.001 ; 30-s$ 
- 3-min: $\mathrm{p}=0.001 ; 30$-s -5 -min: $\mathrm{p}=0.001$ ) and 1-min intervals were found to be more intense than 3- and 5-min (1 - 3-min: $\mathrm{p}=0.001 ; 1-5$-min: $\mathrm{p}=0.001)$. Finally, significant differences were obtained when comparing 3- to 5-min $(\mathrm{p}=0.001)$.

\section{Fixed - Periods}

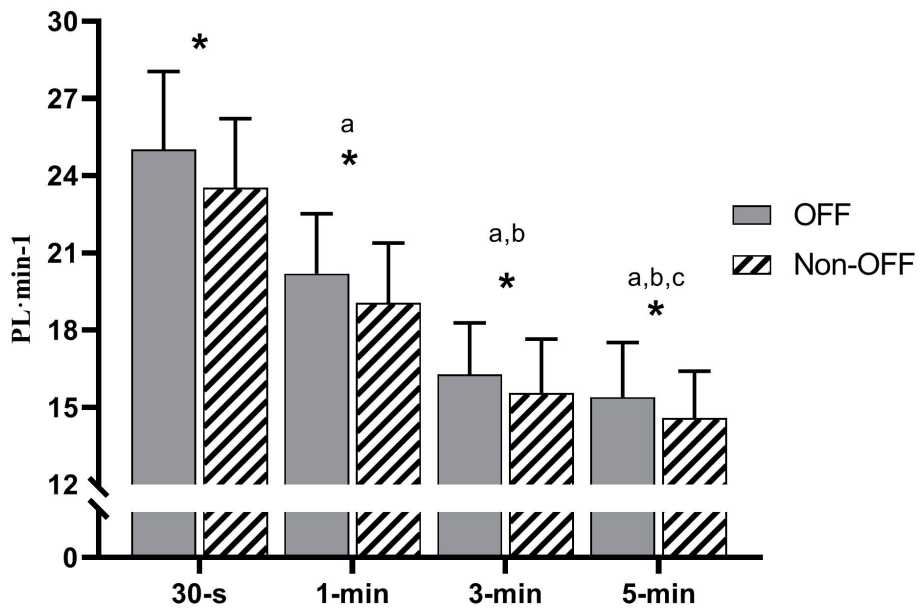

Fig. 2. Worst-case scenarios in official and non-official matches calculated over fixed-periods of 30-s 1-min, 3-min and 5 -min in length.

Values expressed as mean $\pm \mathrm{SD}$.

${ }^{*} \mathrm{p} \leq 0.05$; significant difference between official and non-official analyzed by an Independent T-Test.

a: significantly different than the 30-s time-interval; b: significantly different than the 1-min time-interval;

c: significantly different than 3-min time-interval. OFF: official; Non-OFF: non-official.

Table 1 describes the differences in WCS between the two methods (i.e., ROLL vs FIX). Significant and trivial to moderate differences were obtained between the two methods considering 30-s $(\mathrm{p}=0.001 ; \mathrm{ES}=0.98), 1-\min (\mathrm{p}=0.001 ; \mathrm{ES}=0.97)$, and 3 -min $(\mathrm{p}=$ $0.001 ; \mathrm{ES}=0.18$ ) periods. In contrast, non-significant and trivial differences were found for 5-min intervals $(\mathrm{p}=0.107$; $\mathrm{ES}=-0.18)$.

Table 1. The differences in the intensity calculated by rolling averages and fixed-periods among time-windows

\begin{tabular}{ccccccc}
\multirow{2}{*}{ Time -Window } & \multicolumn{2}{c}{ PL· min $^{-1}$ (a.u.) } & Mean Diff (\%) & p value & ES & $95 \% \mathrm{Cl}$ \\
\cline { 2 - 4 } & Rolling & Fixed & & & & \\
\hline 30-s & $26.1 \pm 2.84$ & $24.2 \pm 2.93$ & $1.77 \pm 0.12$ & 0.001 & 0.98 & $0.83-1.13$ \\
1-min & $21.2 \pm 2.21$ & $19.6 \pm 2.39$ & $1.70 \pm 0.10$ & 0.001 & 0.97 & $0.82-1.12$ \\
3-min & $16.2 \pm 1.68$ & $15.9 \pm 2.08$ & $0.47 \pm 0.10$ & 0.001 & 0.18 & $0.06-0.30$ \\
5-min & $14.6 \pm 1.69$ & $14.9 \pm 2.00$ & $-0.14 \pm 0.11$ & 0.107 & -0.18 & $-0.30--0.05$ \\
\hline
\end{tabular}

Data presented as mean $\pm \mathrm{SD} ;{ }^{*} \mathrm{p} \leq 0.05$; significant differences analyzed by a Paired Sample T-Test.

a.u.: arbitrary unit; $\mathrm{Cl}$ : confidence interval; Diff: difference; ES: effect size; min: minutes; SD: standard deviation; s: seconds.

\section{DISCUSSION}

To our knowledge, this is the first study that compared the WCS between OFF and Non-OFF matches considering different time-periods in futsal. The main findings indicate that 1) the ROLL approach showed that OFF matches present higher intensity (i.e., PL· $\min ^{-1}$ ) when short time-intervals (i.e., 30-s and 1-min) are considered in comparison to Non-OFF; however, no differences exist between games when analyzing large time-windows (i.e., 3- and 5-min); 2) significant differences were observed between matches in all time-periods when using 
the FIX method; 3) significantly higher WCS were determined as time-epochs increased in duration from 30-s to 5-min irrespective of the approach used; and 4) when compared to ROLL, FIX underestimates the WCS in 30-s, 1-, and 3-min intervals but not 5-min.

Match-play intensity during OFF competitions (e.g., LNFS and UEFA Futsal Champions League), as determined by PL· $\mathrm{min}^{-1}$ and calculated via ROLL, was found to be higher than during Non-OFF matches when considering the time-windows of 30-s and 1-min. This could be explained by the importance of the OFF games, in which "winning" is the main goal, and players are more likely to engage in maximal intensity efforts as opposed to friendly matches that are mainly focused on developing tactical, technical, and physical capacities [26]. Comparing acceleration, deceleration and metabolic power measures between official and friendly matches in soccer, differences in match activities were identified as well [27]. Moreover, it should be taken into account that Non-OFF games take place mainly during pre-season (i.e., a period of increased training loads) compared to the OFF ones that are held during the season, a period in which, in theory, players are closer to the peak of their performance. Notably, no difference in WCS was found between the matches as timewindows increased (e.g., 3- and 5-min intervals). It appears that larger time-epochs (i.e., $>3$-min) may obscure the most intense periods of the OFF competitions and overlook the "actual intensity" of these matches, possibly because futsal players barely spend $>5$-min on the court due to unlimited substitutions [28]. In brief, WCS calculated over longer intervals seem to be closer to the match average intensity obtained with the "average approach". From an applied perspective, 30-s and 1-min intervals should be analyzed when determining the WCS, as they are the only ones that allow discriminating between OFF and Non-OFF matches. Moreover, sports practitioners should be conscious that athletes are exposed to high physical stress during friendly matches but that the reached WCS are lower than those of the OFF competitions. Still, Non-OFF should be periodized accordingly, with sufficient recovery (essentially during the preparatory phase) as match time-exposure has been shown to cause more injuries than training time-exposure (i.e., 61.1 injuries/1.000 match hours vs 9.9 injuries/1.000 training hours) during the pre-season [29].

Regarding the different WCS computation methods, the FIX approach underestimated the intensity in futsal matches when compared to the ROLL in 30-s, 1-, and 3-min intervals. These results are in line with previous research from different team-sports $[10,17,18]$. For example, Cunningham et al. [18] found that the FIX method undervalued the maximum and high-speed running distance covered irrespective of the time-window (i.e., 60 - 300s) in rugby players. Similar results were obtained in soccer players, with the FIX method underestimating the relative total and high-speed distances during match-play when compared to ROLL [20]. Interestingly, no significant differences between the two methods were found within the 5-min time-window herein. Again, this finding supports that the utilization of large time-periods to determine the WCS is not recommended, as they do not accurately portrait the game's most demanding passages. The intensity significantly declines as time extends from 30-s to 5-min by both the FIX and ROLL approaches. In applied settings, the WCS provide useful information for practitioners to optimize training and rehabilitation prescription. By better understanding the demands of the most intense periods, coaches can monitor training drills to ensure that players are exposed to such scenarios, particularly in technical-tactical training.

Whilst this is the first study that provides the WCS from an elite futsal team (UEFA Champion League Finalist) in different types of match, it is limited by the fact that only four WCS time-windows (i.e., 30-s, 1-, 3-, and 5-min) and one external load variable (PL- $\mathrm{min}^{-1}$ ) were considered. Furthermore, this study was limited by the small number of players and the fact that only one team was recruited, which leads to analyzing only specific tactical behaviors and the style of the training. Other metrics, such as high-speed running distance 
or accelerations/decelerations, changes of direction, and collisions need to be considered while quantifying the WCS, as they may affect the most intense periods of the game [30]. A holistic approach to the quantification of the WCS that incorporates a range of external and internal load variables is needed in order to provide a better understanding of the most demanding passages during futsal competition because WCS may occur under multivariate conditions as mentioned above [30]. Regarding future research, it would be interesting to analyze how technical-tactical parameters can influence the WCS [30], how these are influenced by the context of situational variables (e.g. 5 vs 4 game in the court, home vs away advantage etc.), and the model of the game and the effectiveness of actions in the match [31]. Lastly, more research comparing the most intense periods of match-play between youth and professional matches to assist practitioners in planning and optimizing long-term player development is warranted.

WCS may provide coaches with useful information to optimize training and rehabilitation practices since a better understanding of the demands of the most intense periods of the game can be used to monitor training drills, particularly during technical-tactical training and allow a more progressive return to competition. From an applied perspective, based on the present data, sport practitioners are advised to use short time-periods (i.e., 30-s and 1-min) to quantify the WCS in futsal as these were the only ones found to be able to discriminate between different types of matches (i.e., OFF and Non-OFF). Conversely, larger time-periods (i.e., 3- and 5-min) appear to obscure the "actual intensity" to which the players are exposed. In addition, ROLL seems to be more accurate than FIX to detect the WCS in elite futsal matches.

\section{CONCLUSIONS}

In line with the initial hypothesis, OFF matches presented higher WCS when compared to Non-OFF competition, quantified by ROLL. However, through this computation method, differences between match types were identified only when short time-intervals (i.e., 30-s and 1-min) were used. Considering the FIX approach, significant differences in WCS between the OFF and Non-OFF games were found in all time-windows. Moreover, this method significantly underestimated the WCS from 30-s to 3-min, but not in the 5-min time-epoch compared to ROLL. Lastly, irrespective of the computation method, 30-s intervals were found to display the highest WCS and 5-min, the lowest.

\section{REFERENCES}

[1] Illa J, Fernandez D, Reche X, Carmona G, Tarragó JR. Quantification of an elite futsal team's microcycle external load by using the repetition of high and very high demanding scenarios. Front Psychol. 2020;11. https://doi.org/10.3389/fpsyg.2020.577624

[2] Spyrou K, Freitas TT, Marín-Cascales E, Alcaraz PE. Physical and physiological match-play demands and player characteristics in futsal: A systematic review. Front Psychol. 2020;11. https://doi.org/10.3389/fpsyg.2020.569897

[3] Spyrou K, Freitas TT, Marín-Cascales E, Herrero-Carrasco R, Alcaraz PE. External match load and the influence of contextual factors in elite futsal. Biol Sport. 2021;39(2):349-54. https://doi.org/10.5114/biolsport.2022.105332

[4] Ribeiro JN, Gonçalves B, Coutinho D, Brito J, Sampaio J, Travassos B. Activity profile and physical performance of match play in elite futsal players. Front Psychol. 2020;11. https://doi.org/10.3389/fpsyg.2020.01709

[5] Barbero-AlvarezJ, Soto V, Barbero-Alvarez V, Granda-Vera J. Match analysis and heart rate of futsal players during competition. J Sport Sci. 2008;26(1):63-73. https://doi.org/10.1080/02640410701287289

[6] Castagna C, D’Ottavio S, Vera JG, Álvarez JCB. Match demands of professional Futsal: a case study. J Sci Med Sport. 2009;12(4):490-4. https://doi.org/10.1016/j.jsams.2008.02.001

[7] Caetano FG, de Oliveira MJ, Marche AL, Nakamura FY, Cunha SA, Moura FA. Characterization of the sprint and repeatedsprint sequences performed by professional futsal players, according to playing position, during official matches. J Appl Biomech. 2015;31(6):423-9. https://doi.org/10.1123/jab.2014-0159

[8] Bekris E, Gioldasis A, Gissis I, Katis A, Mitrousis I, Mylonis E. Effects of a futsal game on metabolic, hormonal, and muscle damage indicators of male futsal players. J Strength Cond Res. 2020. https://doi.org/10.1519/JSC.0000000000003466

[9] Oliva-Lozano JM, Martín-Fuentes I, Fortes V, Muyor JM. Differences in worst-case scenarios calculated by fixed length and rolling average methods in professional soccer match-play. Biol Sport. 2021;38(3):325-31. https://doi.org/10.5114/ biolsport.2021.99706

[10] Oliva-Lozano JM, Rojas-Valverde D, Gómez-Carmona CD, Fortes V, Pino-Ortega J. Worst case scenario match analysis and 
contextual variables in professional soccer players: A longitudinal study. Biol Sport. 2020;37(4):429. https://doi.org/10.5114/ biolsport.2020.97067

[11] Reardon C, Tobin DP, Tierney P, Delahunt E. The worst case scenario: Locomotor and collision demands of the longest periods of gameplay in professional rugby union. PLoS One. 2017;12(5):e0177072. https://doi.org/10.1371/journal.pone.0177072

[12] Johnston RD, Murray NB, Austin DJ, Duthie G. Peak movement and technical demands of professional australian football competition. J Strength Condition Res. 2021 Oct 1;35(10):2818-2823. https://doi.org/10.1519/JSC.0000000000003241

[13] Illa J, Fernandez D, Reche X, Serpiello FR. Positional differences in the most demanding scenarios of external load variables in elite futsal matches. Front Psychol. 2021;12:200. https://doi.org/10.3389/fpsyg.2021.625126

[14] Delves RI, Bahnisch J, Ball K, Duthie GM. Quantifying mean peak running intensities in elite field hockey. J Strength Condition Res. 2021 Sep 1;35(9):2604-2610. https://doi.org/10.1519/JSC.0000000000003162

[15] Cunniffe E, Grainger A, McConnell W, et al. A comparison of peak intensity periods across male field hockey competitive standards. Sports. 2021;9(5):58. https://doi.org/10.3390/sports9050058

[16] Menaspà P. Are rolling averages a good way to assess training load for injury prevention? Br J Sport Med. 2017;51(7):618-9. https://doi.org/10.1136/bjsports-2016-096131

[17] Bradley PS, Sheldon W, Wooster B, Olsen P, Boanas P, Krustrup P. High-intensity running in English FA Premier League soccer matches. J Sport Sci. 2009;27(2):159-68. https://doi.org/10.1080/02640410802512775

[18] Cunningham DJ, Shearer DA, Carter N, et al. Assessing worst case scenarios in movement demands derived from global positioning systems during international rugby union matches: Rolling averages versus fixed length epochs. PloS One. 2018;13(4):e0195197. https://doi.org/10.1371/journal.pone.0195197

[19] Varley MC, Elias GP, Aughey RJ. Current match-analysis techniques' underestimation of intense periods of high-velocity running. Int J Sport Physiol Perform. 2012;7(2):183-5. https://doi.org/10.1123/ijspp.7.2.183

[20] Fereday K, Hills SP, Russell M, Smith J, Cunningham DJ, Shearer D, et al. A comparison of rolling averages versus discrete time epochs for assessing the worst-case scenario locomotor demands of professional soccer match-play. J Sci Med Sport. 2020;23(8):764-9. https://doi.org/10.1016/j.jsams.2020.01.002

[21] Nicolella DP, Torres-Ronda L, Saylor KJ, Schelling X. Validity and reliability of an accelerometer-based player tracking device. PloS One. 2018;13(2):e0191823. https://doi.org/10.1371/journal.pone.0191823

[22] Gaudino P, Iaia F, Alberti G, Hawkins R, Strudwick A, Gregson W. Systematic bias between running speed and metabolic power data in elite soccer players: influence of drill type. Int J Sports Med. 2014;35(6):489-93. https://doi.org/10.1055/s-0033-1355418

[23] Casamichana D, Castellano J. The relationship between intensity indicators in small-sided soccer games. J Hum Kinetics. 2015;46(1):119-28. https://doi.org/10.1515/hukin-2015-0040

[24] Akenhead R, Hayes PR, Thompson KG, French D. Diminutions of acceleration and deceleration output during professional football match play. J Sci Med Sport. 2013;16(6):556-61. https://doi.org/10.1016/j.jsams.2012.12.005

[25] Batterham AM, Hopkins WG. Making meaningful inferences about magnitudes. Int J Sport Physiol Perform. 2006;1(1):50-7. https://doi.org/10.1123/ijspp.1.1.50

[26] Fessi MS, Nouira S, Dellal A, Owen A, Elloumi M, Moalla W. Changes of the psychophysical state and feeling of wellness of professional soccer players during pre-season and in-season periods. Res Sport Med. 2016;24(4):375-86. https://doi.or g/10.1080/15438627.2016.1222278

[27] Nobari H, Khalili SM, Oliveira R, Castillo-Rodríguez A, Pérez-Gómez J, Ardigò LP. Comparison of official and Friendly matches [ through acceleration, deceleration and metabolic power measures: A full-season study in professional soccer players. Int J Environ Res Public Health. 2021;18(11):5980. https://doi.org/10.3390/ijerph18115980

[28] Rico-González M, Pino-Ortega J, Clemente FM, Rojas-Valverde D, Los Arcos A. A systematic review of collective tactical behavior in futsal using positional data. Biol Sport. 2021;38(1). https://doi.org/10.5114/biolsport.2020.96321

[29] López-Segovia M, Fernández V. Preseason Injury Characteristics in Spanish Professional Futsal Players: The LNFS Project. J Strength Condition Res. 2019. https://doi.org/10.1519/JSC.0000000000003419

[30] Novak AR, Impellizzeri FM, Trivedi A, Coutts AJ, McCall A. Analysis of the worst-case scenarios in an elite football team: Towards a better understanding and application. J Sport Sci. 2021:1-10. https://doi.org/10.1080/02640414.2021.1902138

[31] Szwarc A, Oszmaniec M. A model of the efficiency of goalkeepers' actions in futsal. Hun Mot. 2020;21(4):44-53. https:// doi.org/10.5114/hm.2020.95990

Cite this article as:

Spyrou K, Freitas T, Marín-Cascales E, Herrero-Carrasco R, Alcaraz PE.

Differences between official and non-official matches in worst-case scenarios in elite futsal players

Balt J Health Phys Act. 2021;13(4):39-46

doi: 10.29359/BJHPA.13.4.05 